\title{
The experimental verification of the known flow line models describing local flow during ECAE (ECAP)
}

\author{
A. V. Perig ${ }^{\dagger}$, I.S. Galan \\ †olexander.perig@gmail.com
}

Donbass State Engineering Academy, 72 Shkadinova st., 84313, Kramatorsk, Ukraine

In spite of the existence of a number of studies suggesting various models of flow-lines during ECAE, there are few studies dedicated to the experimental visualization of the empirically observable flow-lines. The present research is focused on an experimental verification of the known previously published research results by Han et al (2008), Hasani et al (2008) - Hosseini et al (2009), and Tóth et al (2004) for material flow lines through a die of classical Segal geometry. The experimental research used physical simulation techniques to visualize moving marker trajectories in the vicinity of the channel intersection zone during ECAE of plasticine models. The successive positions of moving markers were recorded with a digital camera with further recognition and digitalization of experimental marker trajectories. This research has shown that experimental flow-lines do not fully fit Toth et al's and Han et al's flow models. It was found that the best fit of experimental flow-lines is achieved by using of Hasani et al's - Hosseini et al's model. Experimental/theoretical results which were obtained in the current study are of interest to the interdisciplinary SPD mechanics sphere. The experimental verification of the earlier published models quoted in the paper provides the succession, sustainability and academic integrity of the experimental/theoretical results from the SPD mechanics of the various schools of sciences. New results of the study relate to the experimental visualization of the moving markers positions during ECAE physical modeling and the experimental/theoretical determination of corresponding empirical flow-lines.

Keywords: Equal Channel Angular Extrusion, kinematics, flow line, particle trajectory, moving marker, physical simulation, layered model, friction, plasticine.

\section{Экспериментальная верификация известных моделей линий тока, описывающих локальное течение при РКУЭ (РКУП)}

\author{
Периг А. В. ${ }^{\dagger}$, Галан И. С.
}

Донбасская государственная машиностроительная академия, ул. Шкадинова 72, 84313, г. Краматорск, Украина

Несмотря на наличие ряда работ, предлагающих различные модели линий тока при РКУП, существует мало исследований, посвященных экспериментальной визуализации эмпирически-наблюдаемых линий тока. Настоящая работа посвящена экспериментальной верификации известных ранее опубликованных научных результатов Нап и др. (2008), Hasani и др. (2008) - Hosseini и др. (2009), а также Tóth и др. (2004) для линий тока материала при РКУП через штамп классической Сегаловской геометрии. Экспериментальное исследование использует методы физического моделирования для визуализации траекторий движущихся маркеров в зоне пересечения каналов при РКУП пластилиновых моделей деформируемых заготовок. Последовательные положения движущихся маркеров были записаны с использованием цифровой камеры с дальнейшим распознаванием и оцифровыванием экспериментальных траекторий маркеров. Настоящее исследование выявило, что экспериментально-полученные линии тока не в полной мере совпадают с моделями Тóth и др. и Нап и др. для РКУП-линий тока. Было установлено, что наилучшее согласование эмпирически-установленных линий тока с ранее опубликованными результатами имеет место для моделей Hasani и др. - Hosseini и др. Экспериментально-теоретические результаты, полученные в рамках представленного исследования, представляют интерес для междисциплинарной сферы ИПД механики. Экспериментальная верификация ранее опубликованных моделей, выполненная в данной работе, способствует преемственности, стабильности и академической достоверности теоретико-экспериментальных результатов по механике ИПД между различными школами исследователей. Оценка условий трения при физическом моделировании РКУП выполнялась в рамках применения методики De Pierre и др. (1972) по осадке 6:3:2 колец, несмотря на отличия параметра NádaiLode в ОМД-схемах РКУП и осадки колец. Новые результаты данного исследования относятся к вопросам экспериментальной визуализации положений движущихся маркеров в рамках физического моделирования РКУП, а также экспериментально-теоретического определения соответствующих эмпирических линий тока.

Ключевые слова: равноканальная угловая экструзия, кинематика, линия тока, траектория частицы, движущийся маркер, физическое моделирование, слоистая модель, трение, пластилин. 


\section{Background}

Further improvement in the growing processes of Severe Plastic Deformation (SPD) requires refinement of existing models and hypotheses, which lay in the foundations of phenomenological continuum mechanics-based descriptions of local flows during equal channel angular extrusion (ECAE) [1-19]. Being one of the oldest and the most famous SPD processes, the ECAE deformation technique still attracts growing attention of scientists in materials science, physics and chemistry. This is evident from the increasing quantity of ECAE-related original research in SCIE- and Scopusindexed journals.

Accurate determination of kinematically admissible flow line shapes during ECAE is very important along with correct accounting of such deformed materials rheologic properties as viscous and plastic features of the local flow. The flow line field enables visual determination of the location and boundaries of a dead zone.

\section{Introduction. The state of the art}

Over the last 20 years a number of continuum phenomenological models by $\mathrm{Han}$ et al (2008) [1] (Fig. 4-5), Hasani et al (2008) [2] (Fig. 6-7), Hosseini et al (2009) [3] (Fig. 6-7), Kucheryaev (2006) [4], Laptev et al (2014) [5], Perig et al (2010-2017) [6-18], Tóth et al (2004) [19] (Fig. 1-2) etc have been proposed for the geometric description of kinematically-admissible ECAE flow lines and flow velocities during local flow of ECAE-worked materials through angular domains with different die geometries (all figures are placed in the end of the text).

The common features of Tóth et al's (2004) [19] (Fig. 1-2) and Han et al's (2008) [1] (Fig. 4-5) ECAErelated phenomenological models are based on a priori assignment of the form of a prescribed kinematically admissible flow function as an aprioristic givenness with no further description, background, nor discussion of the shape of this flow function.

Tóth et al's (2004) phenomenological model [19] (Fig. 1-2) has two available "degrees of freedom", which determine a possible geometric shape of flow lines in an angular domain of an ECAE die through the introduction of a power index $n$ and an initial horizontal coordinate $x_{0}$ for a chosen flow line. Tóth et al's (2004) model (Fig. 1-2) implicitly assumes symmetry of the dead zone with respect to the bisector of the die channel intersection zone and, as result, assumes the fulfillment of the incompressibility condition for ECAE worked material [19].

There are a number of known research efforts which analyze, develop and implement fan-like models of flow lines during ECAE (Fig. 4 -5), where kinematically admissible flow lines have the shapes of symmetric families of concentric flow lines within the bisector-symmetric fan in the deformation region. This flow line family is restricted to symmetric curvilinear external arcs, which are based on symmetric dead zones within the framework of the validity of the hypothesis of incompressibility.

Han et al.s (2008) research assumes material flow lines as concentric arcs of circles within the deformation zone of an
ECAE die [1] (Fig. 4-5), while Hasani et al (2008) [2] and Hosseini et al (2009) [3] (Fig. 6-7) assume material flow lines as concentric elliptical arcs.

The second edition of Kucheryaev's (2006) textbook on Continuum Mechanics contains several interconnected examples which illustrate estimations of geometric, kinematic, and energy-power parameters of the ECAE process [4]. New enhanced algebraic expressions, which describe the flow function in the angular die region, estimate deformation heating of ECAE-worked material, and determine an average ECAE pressure at the pressure plate (ram back-pad) in section 3.1.4,pp. 391 - 393, problem 3.1.4.1 of Kucheryaev's (2006) textbook [4]. Kucheryaev (2006) has applied the analytical techniques of function theory of complex variables to the calculation of the values of SchwarzChristoffel integrals in an ECAE-related problem 3.2.1.2 on pp. $398-409$ that enabled the determination of a continuous velocity field within the region of an angular die of Segal geometry, and kinematic parameters of the ECAE process [4]. Kucheryaev (2006) has derived numerical estimations for dependence of ECAE punching pressure with respect to die channel intersection angle as well as graphical plots for isolines of the base (main) and corrected (adjusted) velocity field during ECAE using complex variables analysis [4]. At the same time Kucheryaev's (2006) textbook lacks important details concerning the derivation of numerical values of the kinematic and energy-power parameters of the ECAE process [4]. Formal Kucheryaev's commentaries concerning the performed minimization of certain functionals provide insufficient clearness of the minimization process and the derived results, and a physical explanation of derived results of the mathematical simulation [4]. Despite the large quantity of cumbersome mathematical expressions on pp. $391-393$ and pp. 398-415, Kucheryaev's solution of the ECAE problem lacks a lot of important details concerning practical applications of Kucheryaev's mathematical expressions on pp. $391-415$ to the practical needs of ECAE computation [4].

A model describing the Equal-Channel Angular Extrusion (ECAE) flow-lines family and defined by three geometric parameters $\alpha, n$ and $\mu$ was proposed by Hasani et al (2008) [2] and additionally analyzed by Hosseini et al (2009) [3] (Fig. $6-7$ ). Powered by $n$, the sine and cosine of subsidiary angle $\alpha$ allow correcting flow-lines asymmetry relative to the channel crossing angle bisector. The $\mu$ parameter controls the $y$-coordinate of the flow-line and outlet plastic deformation zone boundary crossing point [2-3].

Wolfram Mathematica [20] and MatLab languages are powerful computational tools which are effectively used for movable marker recognition in the series of experimental applied velocimetry photos in Fig. 1-7.

\section{Aims and scopes of the article. Novelty}

The purpose of the current paper is to experimentally verify Tóth et al's (2004) [19] (Fig. 1-2), Han et al's (2008) [1] (Fig. 4-5) and Hasani et al's (2008) [2] - Hosseini et al's (2009) [3] (Fig. 6-7) models within the framework of physical modeling of an equal-channel angular extrusion through a classical angular die model of Segal geometry 
with a transparent plexiglass frontal cover and a right angle inlet/outlet channel crossing (Fig. 1-8, 11).

The object of the current study is to experimentally describe the process of equal-channel angular extrusion (Fig. 1-11) by using soft deforming material models with implanted solid particles at the frontal surface of the model as moving geometric markers (Fig. 1-7).

The subject of the current study is the local geometrical features of experimental and the kinematically-possible flowlines in the plastic deformation focus zone during ECAE.

The experimental method used is physical modeling of local flow during ECAE using marker particles in a soft model material; the theoretical geometric method for marker particle position recognition on the series of experimental digital photos was implemented with Wolfram Mathematica; the compositional method of the collective graphical plotting of the experimental and theoretical trajectories were obtained with the known Tóth et al's (2004) [19] (Fig. 1 -2), Han et al's (2008) [1] (Fig. 4 - 5) and Hasani et al's (2008) [2] - Hosseini et al's (2009) [3] (Fig. 6-7) models.

Main contribution: In spite of the existence of a number of studies suggesting various models of flow-lines during ECAE, there are few studies dedicated to the experimental visualization of the empirically observable flow-lines during ECAE. The main contribution of the current paper to the sphere of SPD and ECAE is the experimental and theoretical determination of the empirical flow-lines during ECAE on a plasticine model through an angular die of classical Segal geometry and the critical collation of the obtained results with the known models.

Prime novelty: new results of the study relate to the experimental visualization of the moving markers positions during ECAE physical modeling and the experimental/theoretical determination of corresponding empirical flow-lines.

Scope of application: experimental/theoretical results which were obtained in the current study are of interest to the interdisciplinary SPD mechanics sphere. The experimental verification of the earlier published models quoted in the paper provides the succession, sustainability and academic integrity of the experimental/theoretical results from the SPD mechanics of the various schools of sciences.

\section{Methods and research limitations}

\subsection{Choice of a suitable deviation measurement between flow lines}

It is very important to note that there is a problem in determining experimental flow lines in Fig. 1-7 with experimental-analytical methods, such as through approximation of experimental data with further smoothing. According to terminology proposed by academician Andrey N. Tikhonov, this is an error problem or an incorrect problem. Error in flow lines determination means that a small change in the initial data results in a large change in the solution. Moreover, there are no unique criteria for the selection of proper approximations. Indeed, there is no single "true" approximation and the single-value condition is violated. Wolfram Mathematica-based recognition of experimental flow lines in Fig. 1-7 is the solution of experimentally-derived flow lines with Wolfram-based regularization [20].

This is a very important question in selecting the measure of deviation between the author-derived experimental flow lines and the published theoretical ones. Some suggestions concerning the choice of a dimensional measure of deviation between two curves are given on p. 56, paragraph 36, Chapter VI of a textbook by Lavrentiev and Lusternik (1935) [21], who determined the dimensional distance between two curves $y=y(x)$ and $y=y_{1}(x)$ as a maximum of absolute values of abs $\left(y_{1}(x)-y(x)\right)$ at segment $x_{0} \leq x \leq x_{1}$ [21]. Another definition of a dimensional measure of deviation between two curves is provided on p. 436, paragraph 6, Chapter 17 of a workbook on mathematics by Efimov et al. (2002) [22], who determined the dimensional distance $\rho\left(y_{1}, y_{2}\right)$ between two curves $y_{1}(x)$ and $y_{2}(x)$ in linear normalized (normed) space $C_{n}[a ; b]$ as

$$
\rho\left(y_{1}, y_{2}\right)_{n}=\sum_{n}^{k=0} \max \left|y_{1}^{(k)}(x)-y_{2}^{(k)}(x)\right|
$$

where $y^{(k)}(x)$ denotes the continuous derivative of $k$-th order; $a \leq x \leq b$; $k$ is the order of derivative, which varies in the range of $0 \leq k \leq n ; n=0,1, \ldots$ [22].

Following the "y-based" approach by Lavrentiev \& Lusternik (1935) [21] and Efimov et al. (2002) [22], authors of the present research have introduced a dimensionless relative parameter $y(x) / y_{1}(x)=y_{\text {theoretical }} / y_{\text {experimental }}$ between ordinates of two compared flow lines in the space $C_{0}[a ; b](n=0)$, which was used by the authors as a dimensionless measure of deviation between theoretical and experimental flow lines.

Surely it is very important to eventually find a more sophisticated measure of deviation between flow lines that is more sound, not only for better approximation of ECAE flow lines, but also suitable for taking into account strain rate and material deformation, which depend on flow line derivatives. In further research the authors will compare flow lines, which would be grounded on different approximations of flow (stream) functions and would be recovered from the same experimental data. A more sophisticated measure of deviation between flow lines should be based on the distances in spaces $C_{1}[a ; b](n=1)$ and $C_{2}[a ; b](n=2)$, where the authorchosen value of $n=\{1,2\}$ for linear normalized space $C_{n}[a ; b]$ is dependent on the highest order of the used derivatives [22]. However the comparison of flow lines in spaces $C_{1}[a ; b]$ for correctness of working with first-order derivatives of flow function and $C_{2}[a ; b]$ for more accurate accounting of availability of second-order derivatives of stream function is beyond the scope of the present article and will be the matter of further research studies.

\subsection{Concerning friction conditions and friction similarity}

An accurate geometric analysis of visually observable experimental flow lines in Fig. 1 - 7 requires an experimental estimation of friction conditions which are acting on the front surface, back surface, and lateral sides of the plasticine model of ECAP workpiece model in the present research study. At the initial moment of time the non-deformed plasticine workpiece model had a first shape of a rectangular parallelepiped, which was placed at different friction 
conditions because the front surface of plasticine model was in contact with transparent Plexiglas wall, and back \& lateral surfaces of plasticine model were in contact with wooden walls of ECAE die model.

Therefore a successful physical simulation required the authors to make an approximate experimentally-based estimation of numerical values of friction coefficient $f$ in Amantons \& Coulomb friction law $\tau_{f}=f \cdot \sigma_{n}$ and friction factor $m$ in Siebel (Tresca) friction law $\tau_{f}=m \cdot k$ for the contact friction pairs of materials "plasticine model Plexiglas wall" and "plasticine model - wooden wall", where $\tau_{f}$ is friction induced shear stress; $\sigma_{n}$ is normal stress, and $k$ is plastic constant of plasticine material of workpiece model. Authors decided to make the first estimation of $m$ and $f$ numerical values with an introduction of De Pierre et al's (1972) experimental technique [23], based on successive step-by-step upsetting of placticine rings with a ratio of initial dimensions $D: d: H=6: 3: 2$ between two upper and lower Plexiglas plates and between two upper and lower wooden plates, where $D \& d$ are external and internal radii, and $H$ is the height of the plasticine rings. The authors were aware that the application of De Pierre et al's (1972) experimental approach [23] for estimation of friction factor $m$ and friction coefficient $f$ using corresponding calibrating planes neglects the fundamental distinctions between Nádai-Lode factors in such different forming schemes as angular pressing (ECAE) and upsetting. However the authors used this method [23] for simple preliminary estimation of friction conditions for ECAE schemes in Fig. 1-11. It might be appropriate to consider the use of similarity theory and introduce the following dimensionless friction similarity number $\Pi=m / f=$ idem.

For the friction pair "plasticine - Plexiglas," an average value of friction factor $m=0.318$ was experimentally determined by upsetting 35 plasticine 6:3:2 rings between two Plexiglas plates, the average friction coefficient was $f=0.079$, and the dimensionless friction similarity number was $\Pi_{\mathrm{pp}}=0.318 / 0.079=4.025$ in Fig. $1-8,10-11$.

For the friction pair "plasticine - wood," an average value of friction factor $m=0.594$ was experimentally determined by upsetting 65 plasticine $6: 3: 2$ rings between two smooth wooden plates, the average friction coefficient was $f=0.181$, and the dimensionless friction similarity number was $\Pi_{\mathrm{pw}}=0.594 / 0.181=3.282$ in Fig. $1-8,10-11$.

These experimentally-derived values of friction coefficients enhance the understanding of friction conditions for empirical ECAE flow lines in Fig. 1-8, 10-11.

It is important to note that additional experiments with upsetting of $6: 3: 2$ rings, which were made from different models of worked materials, provide possibility for estimation of friction-based similarity between ECAE flows of continua with different materials' rheology. It is useful to add friction conditions for such physical models as wax, copper and lead $6: 3: 2$ rings.

For the friction pair "wax - Plexiglas", an average value of friction factor $m=0.532$ was experimentally determined by upsetting 35 wax $6: 3: 2$ rings between two Plexiglas plates, the average friction coefficient was $f=0.120$, and the dimensionless friction similarity number was $\Pi_{\mathrm{wp}}=0.532 / 0.120=4.433$.
For the friction pair "wax - wood," an average value of friction factor $m=0.724$ was experimentally determined by upsetting 20 wax $6: 3: 2$ rings between two smooth wooden plates, the average friction coefficient was $f=0.177$, and the dimensionless friction similarity number was $\Pi_{\mathrm{ww}}=0.724 / 0.177=4.090$.

For the friction pair "copper - steel," an average value of friction factor $m=0.532$ was experimentally determined by upsetting 18 copper 6:3:2 rings between two smooth steel plates, the average friction coefficient was $f=0.124$, and the dimensionless friction similarity number was $\Pi_{\mathrm{cs}}=0.532 / 0.124=4.290$.

For the friction pair "lead - steel," an average value of friction factor $m=1.0$ was experimentally determined by upsetting 19 lead 6:3:2 rings between two smooth steel plates, the average friction coefficient was $f=0.285$, and the dimensionless friction similarity number was $\Pi_{\mathrm{Ls}}=1.0 / 0.285=3.509$.

It is possible to make some important conclusions concerning ECAE flow similarities through the application of the pi theorem of friction similarity in the form of $\Pi=m / f=$ idem.

The similar values of $\Pi_{\mathrm{pw}}=\Pi_{\mathrm{Ls}} \quad\left(\Pi_{\mathrm{pw}}=3.282\right.$ and $\left.\Pi_{\mathrm{Ls}}=3.509\right)$ allow an approximate statement that ECAE flow of a plasticine workpiece model through a wooden angular die model (Fig. 1-8, 10-11) is frictionally similar to ECAE flow of a lead workpiece model through a steel angular die model.

The similar values of $\Pi_{\mathrm{pp}}=\Pi_{\mathrm{ww}} \quad\left(\Pi_{\mathrm{pp}}=4.025\right.$ and $\Pi_{\mathrm{ww}}=4.090$ ) allow an approximate statement that ECAE flow of a plasticine workpiece model through a Plexiglas angular die model (Fig. 1-8, 10-11) is frictionally-similar to ECAE flow of a wax workpiece model through a wooden angular die model.

The similar values of $\Pi_{\mathrm{wp}}=\Pi_{\mathrm{cs}}\left(\Pi_{\mathrm{wp}}=4.433\right.$ and $\left.\Pi_{\mathrm{cs}}=4.290\right)$ allow an approximate statement that ECAE flow of a wax workpiece model through a Plexiglas angular die model is frictionally-similar to ECAE flow of a copper workpiece model through a steel angular die model.

The complex of new experimentally-derived results (Fig. 1-11) and pi theorem-based frictional similarity considerations surely broadens the understanding of the mechanics of local ECAE flow of model materials from rheological and friction-based viewpoints.

\subsection{ECAE-induced material flow lines and layered physical models}

Some specialists in materials science and experimental mechanics of materials believe that it is possible to make a more exact determination of material flow lines during ECAE-induced deformation of layered physical models of pressure formed workpieces. Authors of the present research performed a number of experimental studies of ECAE flow of layered workpiece models, shown in Fig. 8-10 and have found that the boundary of every layer of the deformed workpiece model differs fundamentally from material flow lines during ECAE and therefore the use of layered workpiece models has no advantages for flow lines identification in comparison with the use of a particle-marker in Fig. 1-7. 
Moreover, author-derived experiments with ECAE of layered models in Fig. 8-10 clearly show a number of complexities and ambiguities associated with the preparation of workpiece models in the form of an assembly of short multiple layers with initial perpendicular orientation (Fig. 8 -9) and parallel orientation (Fig. 10) to the ECAE inlet channel die.

The geometry of the initial positioning of the multilayered workpiece model within the angular die in Fig. 8(a) has an important influence on all results of the physical simulation. The initial location of the non-deformed multilayered workpiece model does not coincide with the bottom surface of the outlet die channel in Fig. 8(a). The initial workpiece model is a compound multi-layered parallelepiped, which consists of alternating yellow and green block layers with initial rectangular cross sections in Fig. 8(a).

It is shown in Fig. 8(b) that the step-by-step punch displacement along the inlet die channel causes partial separation and stratification of the lower free layers of the plasticine model, which still have no contact with the bottom surface of the outlet die channel. Fig. 8(b) also shows visible processes of crushing, dithering and formation of $\mathrm{V}$ - and $\mathrm{U}$-shaped forms in upper layers of the workpiece model, which are adjacent to the punch surface.

Fig. 8(c) shows the classical beginning of the ECAE process. At this stage approximately $80 \%$ of the bottom outer yellow layer of the workpiece model comes into full contact with the bottom surface of the outlet die channel. At this stage, additional barrel distortion occurs within the two adjacent plasticine layers of the workpiece model, which will form the body of the workpiece model in the outlet die channel. The upper layers of the model are reaching very high levels of plastic deformation, which causes defacing of the borders between individual layers as well as excessive wedging out of workpiece layers.

Empirical data in Fig. 8(d) clearly shows the formation of the workpiece surface within the outlet die channel, which includes the five bottom layers of the plasticine model. No symmetry of the formed workpiece with respect to the symmetry axis of the outlet die channel is observable at this stage of deformation.

Fig. 8(e) depicts the further formation of the workpiece within outlet die channel, which includes three yellow and two green bottom layers. It is clearly observable in Fig. 8(e) that the boundary of the yellow and green plasticine layers, which are adjacent to the bottom surface of the outlet die channel, is not the boundary of the material dead zone. Therefore it is not correct to identify the boundaries of the layers with kinematically admissible flow lines.

Fig. 8(f) shows the formation of an additional crack at the foot of the model, which is in contact with the bottom surface of the outlet die channel. Fig. 8(f) additionally confirms the inadmissibility of superposition of layers' boundaries with material flow lines at this ECAE stage.

Successive Fig. 8(g),(h),(i) illustrate successive growing crack formation in the workpiece model foot, which quickly develops due to the large contact friction with the bottom surface of the outlet die channel. Fig. 8(g), (h), (i) also show the formation and development of additional loosening of workpiece material within the upper part of the workpiece in the outlet die channel, which is associated with performance of ECAE without back-pressure in the outlet channel (compare with Fig. 11).

Experimental data in Fig. 8-10 clearly show that it is a highly incorrect idea to attempt to correlate layer boundaries and material flow lines.

\section{Experimental-theoretical research results}

Plasticine was used as the first rheological approach for local continuum during ECAE. Plasticine is applied to modeling of metal forming with hot metal working processes as well as for polymer rheology modeling. Local flow modeling was provided by setting up a frontal plexiglass cover for the detachable die. The movement of implanted particles was visualized. Implanted particles were represented by spherical markers which were partially immersed into the plasticine model and attached to the frontal die wall surface. Consecutive moving marker positions fixation was implemented by the camera shot series of digital photos consisting of 11 pieces in the first experiment N1 (Fig. 1,3,4,6) and 11 pieces in the second experiment N2 (Fig. 2,5,7). The camera was set up on the fixed platform in front of the deformation focus zone (Fig. 1-7). Moving marker positions of 11 (experiment N1) and 11 (experiment N2) experimentally-derived digital photos were identified, recognized and digitalized using Wolfram Mathematica software [20] as bold green solid lines (- ) in Fig. $1-7$.

From the two conducted experiments the second one obtained the flow-lines which have noticeably more outer trajectories in comparison to those in the marker flow analysis from the digital images created during the first experiment. The statistical analysis shows that the mean deviation between flow-lines from the first and the second experiments is $25.13 \%$, the confidence interval is $0.875 \leq\left(y_{\exp 1} / y_{\exp 2}\right) \leq 1.125$ for the confidence level 0.95 , and the confidence interval is $0.831 \leq\left(y_{\exp 1} / y_{\exp 2}\right) \leq 1.169$ for the confidence level 0.99 .

The results of the comparison of the authors'-derived experimental results as bold green solid lines ( - ) in Fig. 1 - 7 were compared with known ECAE models as dark blue solid lines $(-)$ by Tóth et al (2004) [19] (Fig. 1-2), Han et al (2008) [1] (Fig. 4-5), Hasani et al (2008) [2] Hosseini et al (2009) [3] (Fig. 6-7). Comparison with modified Tóth et al's (2004) [19] model is shown in Fig. 3.

Results of the comparison have shown that the authors' derived experimental results for the first experiment $\mathrm{N} 1$ have the largest disagreement with classical Tóth et al.s (2004) [19] model in Fig. 1, where the maximum relative discrepancy between curves is $\delta_{\max 11}=30.60 \%$; the confidence interval is $0.877 \leq\left(y_{\text {Tóth }} / y_{\text {exp } 1}\right) \leq 1.123$ for the confidence level 0.95 , and the confidence interval is $0.833 \leq\left(y_{\text {Tóth }} / y_{\exp 1}\right) \leq 1.167$ for the confidence level 0.99 .

For minimization of disagreement between curves in Fig. 1 for the first experiment N1 authors of the present research slightly modified Tóth et al.s (2004) [19] model as is shown in Fig. 3. Modification of Tóth et al.s model in Fig. 3 with introduction of two different power indices resulted in a decrease of the maximum relative discrepancy between curves to $\delta_{\max 12}=9.10 \%$; the confidence interval is $0.949 \leq\left(y_{\text {modified Tóth }} / y_{\exp 1}\right) \leq 1.051$ for the confidence level 0.95, 
and the confidence interval is $0.931 \leq\left(y_{\text {modified Toth }} / y_{\text {exp } 1}\right) \leq 1.069$ for the confidence level 0.99 .

The second-best comparison results take place for Han et al's (2008) [1] model and are shown in Fig. 4 for the first experiment $\mathrm{N} 1$, where the maximum relative discrepancy between curves is $\delta_{\max 13}=5.56 \%$; the confidence interval is $0.973 \leq\left(y_{\text {Han }} / y_{\exp 1}\right) \leq 1.025$ for the confidence level 0.95 , and the confidence interval is $0.963 \leq\left(y_{\text {Наn }} / y_{\text {exp }}\right) \leq 1.034$ for the confidence level 0.99 .

The best comparison results take place for Hasani et al's (2008) [2] - Hosseini et al's (2009) [3] model and are shown in Fig. 6 for the first experiment N1, where the maximum relative discrepancy between curves is $\delta_{\max 14}=1.12 \%$; the confidence interval is $0.994 \leq\left(y_{\text {Hasani }} / y_{\text {exp } 1}\right) \leq 1.006$ for the confidence level 0.95 , and the confidence interval is $0.991 \leq\left(y_{\text {Hasani }} / y_{\exp 1}\right) \leq 1.008$ for the confidence level 0.99 .

It is important to note that the successive values of the maximum relative discrepancies are decreasing numbers $\delta_{\max 1 i}=\left\{\delta_{\max 11} ; \delta_{\max 12} ; \delta_{\max 13} ; \delta_{\max 14}\right\}$ or $\delta_{\max 1 i}=\{30.60 \% ; 9.10 \%$; $5.56 \% ; 1.12 \%$, where $\delta_{\max 11}>\delta_{\max 12}>\delta_{\max 13}>\delta_{\max 14}$.

Results of the comparison have shown that the authors'derived experimental results for the second experiment $\mathrm{N} 2$ have the largest disagreement with classical Tóth et al.s (2004) [19] model in Fig. 2, where the maximum relative discrepancy between curves is $\delta_{\max 21}=9.24 \%$; the confidence interval is $0.948 \leq\left(y_{\text {Tóth }} / y_{\text {exp } 2}\right) \leq 1.052$ for the confidence level 0.95 , and the confidence interval is $0.929 \leq\left(y_{\text {Toth }} / y_{\exp 2}\right) \leq 1.071$ for the confidence level 0.99 .

The second-best comparison results take place for Han et al's (2008) [1] model and are shown in Fig. 5 for the second experiment $\mathrm{N} 2$, where the maximum relative discrepancy between curves is $\delta_{\max 22}=7.66 \%$; the confidence interval is $0.942 \leq\left(y_{\text {Han }} / y_{\exp 2}\right) \leq 1.055$ for the confidence level 0.95 , and the confidence interval is $0.921 \leq\left(y_{\text {Han }} / y_{\exp 2}\right) \leq 1.074$ for the confidence level 0.99 .

The best comparison results take place for Hasani et al's (2008) [2] - Hosseini et al's (2009) [3] model and are shown in Fig. 7 for the second experiment N2, where the maximum relative discrepancy between curves is $\delta_{\max 23}=7.60 \%$; the confidence interval is $0.951 \leq\left(y_{\text {Hasani }} / y_{\text {exp } 2}\right) \leq 1.047$ for the confidence level 0.95 , and the confidence interval is $0.933 \leq\left(y_{\text {Hasani }} / y_{\exp 2}\right) \leq 1.064$ for the confidence level 0.99 .

It is important to note that the successive values of the maximum relative discrepancies are decreasing numbers $\delta_{\max 2 i}=\left\{\delta_{\max 211} ; \delta_{\max 222} ; \delta_{\max 23}\right\}$ or $\delta_{\max 2 i}=\{9.24 \% ; 7.66 \% ; 7.60 \%\}$, where $\delta_{\max 21}>\delta_{\max 22}>\delta_{\max 23}$.

\section{Discussions}

Repeatability and reproducibility of experimental results was confirmed by running two experiments with ECAEassisted displacement of a point marker, where comparative results for experiments $\mathrm{N} 1$ and $\mathrm{N} 2$ are shown in Fig. 1, 3, 4,6 and Fig. 2,5,7 respectively. The general trends in relative disagreements between flow lines in Fig. 1-7 were found and estimated. It was found with the first experiment N1 in Fig. 1,3,4,6 that the maximum disagreement of $30.6 \%$ occurs between experimental and the standard Tóth et al's (2004) [19] flow lines (Fig. 1); a lower divergence of $9.1 \%$ is between experimental and the modified Tóth et al's (2004)
[19] flow lines (Fig. 3); even lower discrepancy $5.56 \%$ is shown between experimental and Han et al's (2008) [1] (Fig. 4) models, and the minimum disagreement $1.12 \%$ occurs between experimental and Hasani et al's (2008) [2] Hosseini et al's (2009) [3] model (Fig. 6). It was found with the second experiment N2 in Fig. 2,5,7 that the maximum disagreement $9.24 \%$ takes place between experimental and the standard Tóth et al's (2004) [19] flow lines (Fig. 2); lower divergence $7.66 \%$ is between experimental and Han et al's (2008) [1] (Fig. 5) models, and the minimum disagreement $7.60 \%$ occurs between experimental and Hasani et al's (2008) [2] - Hosseini et al's (2009) [3] model (Fig. 7).

There are the very important questions concerning disagreement between flow lines, which are associated with the variation of rheological characteristics of deformed materials, i.e. concerning discrepancies between flow lines of plasticine and metals. It was reported in previous published research works [1] - [3], [19] that Tóth et al's (2004) model [19], Han et al's (2008) model [1], and Hasani et al's (2008) [2] - Hosseini et al's (2009) [3] model excellently fit experimentally-observable flow lines during ECAE of metal workpieces. Therefore it is possible to assume that the above mentioned percent values of quantitative disagreements between theoretical and plasticine flow lines may be regarded as approximate values of numerical divergences between metal flow lines and plasticine flow trajectories.

It is shown in Fig. 1-7 that the graphical plots of the standard (Fig. 1 - 2) \& modified (Fig. 3) Tóth et al's (2004) [19] as well as Han et al's (2008) [1] (Fig. 4-5) models maintain the sign of the second derivative, because the algebraic structures of the corresponding phenomenological expressions, published in [19] \& [1], ensure sign maintenance. However Hasani et al's (2008) [2] - Hosseini et al's (2009) [3] model in Fig. 6-7 has more algebraic parameters, which provide more degrees of freedom of [2] - [3] the theoretical flow lines for better fitting and a more adequate geometric description of author-derived experimental data. Hasani et al's (2008) [2] - Hosseini et al's (2009) [3] expression in Fig. 6- 7 almost coincides with the author-derived experimental results, which show the non-monotonic change of increments of plastic strain, i.e. non-monotonic change of direction of the principal increments of strain. It is important to note that the main indicator of non-monotonicity is not only the quantity of parameters in the published flow line model [2] - [3], but an algebraic structure of phenomenological expression for flow function, which ensures a plot of correspondent flow trajectories with a sign reversal of the second derivative. An important new research result of the present study presents itself in the experimentally-derived data in Fig. 1-7. There is no change of direction of the ECAE punching force but in Fig. 1-7 a non-monotonic deformation occurs for these specific conditions of pressure forming. And this existence of non-monotonicity directly follows from author-derived empirical data in Fig. 1-7. However it is obvious that empirical flow lines, derived with authors experimental data in Fig. 1-7, have the best fitting with Hasani et al's (2008) [2] - Hosseini et al's (2009) [3] model, plotted in Fig. $6-7$. The appearance of non-monotonicity results in the necessity for the use of more complex expressions for interrelations between stresses and strain increments for 
further sophisticated estimations of the workpiece stressstrain state. If even there is no reversal of the sign of the second derivative, then nevertheless the second derivative for Hasani et al's (2008) [2] - Hosseini et al's (2009) [3] flow lines in Fig. 6-7 undergoes substantial changes in comparison with theoretical flow lines in Fig. $1-5$. There is a visually-observable change of the second derivative, i.e. the curvature for both theoretical and experimental flow lines in Fig. 6-7. It is possible in further research studies to set the flow line in Fig. 6-7 as the template (i.e. assume it as the function $y_{1}$ ). Then any other flow line will be located at the certain specific distance $\rho\left(y_{1}, y_{2}\right)_{1}$ or $\rho\left(y_{1}, y_{2}\right)_{2}$ from the template $y_{1}$. Computation of these distances $\rho\left(y_{1}, y_{2}\right)_{1}$ or $\rho\left(y_{1}, y_{2}\right)_{1}$ for different pairs of curves $\left(y_{1}, y_{2}\right)$ will be a matter of further research studies.

It is also very important in further research studies to clarify the question of time variance during ECAE flow. The partial case of truly stationary flow of the left (orange) workpiece is shown in Fig. 11 for the plastic flow of long plasticine model with a back-pressure, caused by the presence of the right (dark blue) workpiece in the outlet die channel. To confirm the absence of time variance in the physical simulation results, authors will need to repeat all physical simulation results in Fig. $1-10$ with the addition of

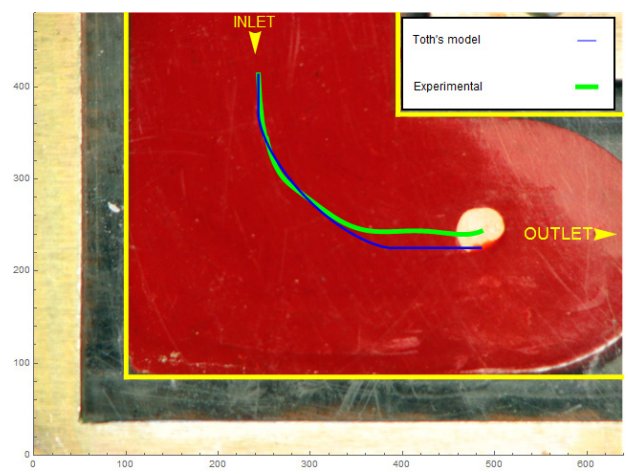

Fig. 1. Geometric verification of Tóth et al's (2004) [19] nonmodified $\left((a-x)^{n}+(a-y)^{n}=\left(a-x_{0}\right)^{n}\right.$; channel width $a=285$ pixels; the initial flow line abscissa $x_{0}=141.313$ pixels; power index $\left.n=1.5\right)$ model $(-)$ by the experimental trajectory $\mathrm{N} 1(-)$, where the maximum relative discrepancy between curves is $30.6 \%$; inlet is from the top and outlet is to the right.



Fig. 3. Verification of Tóth et al's (2004) [19] modified $\left((a-x)^{m}+(a-y)^{p}=\left(a-x_{0}\right)^{m}\right.$; channel width $a=285$ pixels; the initial flow line abscissa $x_{0}=141.313$ pixels; power indices $m=1.6 ; p=1.65$ ) model (-) by the experimental trajectory N1 ( - ), where the maximum relative discrepancy between curves is $9.1 \%$; inlet is from the top and outlet is to the right.
Fig. 11-like back-pressure into outlet die channel. Repetition of all ECAE simulation-related results with a back-pressure application in Fig. 1-10 is beyond the scope of the present research and will be a matter of the further research studies.

\section{Conclusions and Recommendations}

The present research was focused on experimental verification of existing flow lines models during ECAE. The idea of experimental verification was based on the assumption of identity between the experimental trajectory of the markers and the theoretical flow line. Results of the experimental verification allowed making a qualitative estimation of the degrees of conformity of the published flow line models with the experimental results. It was found that the best correlation between results was for the model by Hasani et al (2008) [2] — Hosseini et al (2009) [3] and the largest disagreement occurred for the classical Tóth et al.s (2004) model. The present experimental results additionally show the rheological difference in ECAE flow of metal and polymer workpieces because the experimental material was plasticine, which behaves like a polymer material. The present experimental research will continue for more sophisticated geometric shapes of the known ECAE dies.



Fig. 2. Geometric verification of Tóth et al's (2004) [19] nonmodified $\left((a-x)^{n}+(a-y)^{n}=\left(a-x_{0}\right)^{n}\right.$; channel width $a=230$ pixels; the initial flow line abscissa $x_{0}=91.5654$ pixels; power index $n=2.5$ ) model $(-)$ by the experimental trajectory N1 ( - ), where the maximum relative discrepancy between curves is $9.24 \%$; inlet is from the top and outlet is to the right.

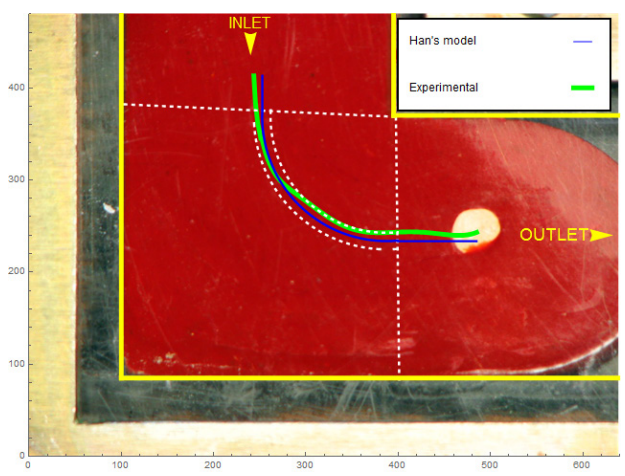

Fig. 4. Geometric verification of Han et al's (2008) [1] $\left((a-x)^{2}+(a-y)^{2}=\left(a-x_{0}\right)^{2}\right.$; channel width $a=285$ pixels; the initial flow line abscissa $x_{0}=141.313$ pixels) model ( - ) by the authors'derived experimental trajectory $\mathrm{N} 1$ ( - ), where the maximum relative discrepancy between curves is $5.56 \%$; inlet is from the top and outlet is to the right. 


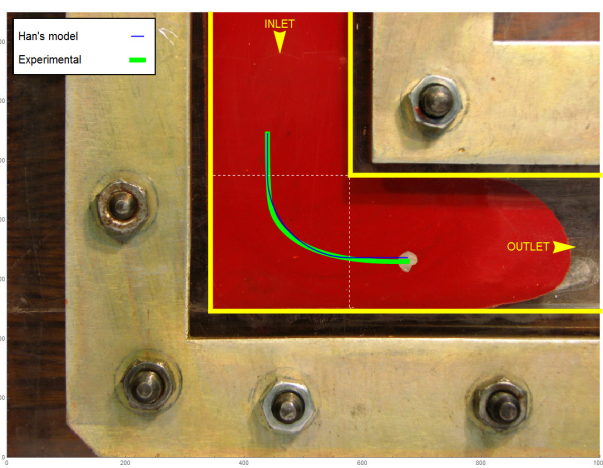

Fig. 5. Geometric verification of Han et al's (2008) [1] $\left((a-x)^{2}+(a-y)^{2}=\left(a-x_{0}\right)^{2}\right.$; channel width $a=230$ pixels; the initial flow line abscissa $x_{0}=91.5654$ pixels) model ( - ) by the authors' derived experimental trajectory N2 (- $)$, where the maximum relative discrepancy between curves is $7.66 \%$; inlet is from the top and outlet is to the right.

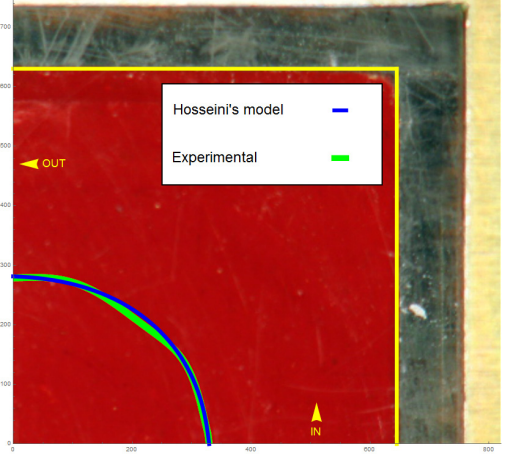

Fig. 6. Geometric verification of Hasani et al's (2008) [2] - Hosseini et al's (2009) [3] $\left((1 / m) \cdot y^{n}+(y \cdot \sin (\alpha)+x \cdot \cos (\alpha))^{n}=\right.$ $=x_{0} \cdot(\cos (\alpha))^{n}$; asymmetry ratio $m=0.7$; angle $\alpha=6.8^{\circ}$; the initial flow line abscissa $x_{0}=329.5$ pixels; power index $n=2.38$ ) model $(-)$ by the authors'-derived experimental trajectory N1 (-), where the maximum relative discrepancy between curves is $1.12 \%$; inlet is from the bottom and outlet is to the left.

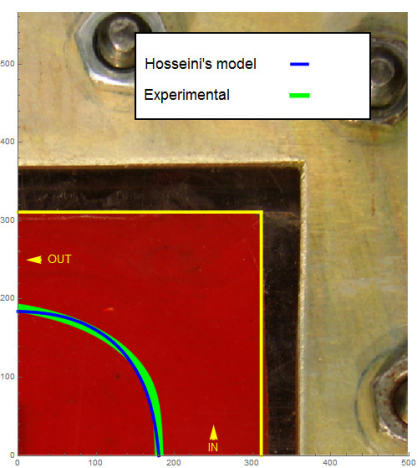

Fig. 7. Geometric verification of Hasani et al's (2008) [2] - Hosseini et al's (2009) [3] $\left((1 / m) \cdot y^{n}+(y \cdot \sin (\alpha)+x \cdot \cos (\alpha))^{n}=\right.$ $=x_{0} \cdot(\cos (\alpha))^{n}$; asymmetry ratio $m=1.08$; angle $\alpha=5.58^{\circ}$; the initial flow line abscissa $x_{0}=180$ pixels; power index $n=2.655$ ) model (-) by the authors'-derived experimental trajectory $\mathrm{N} 2 \quad(-)$, where the maximum relative discrepancy between curves is $7.60 \%$; inlet is from the bottom and outlet is to the left.

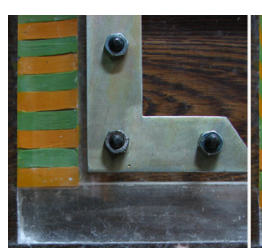

(a)

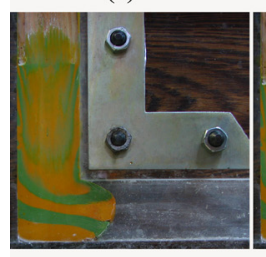

(d)

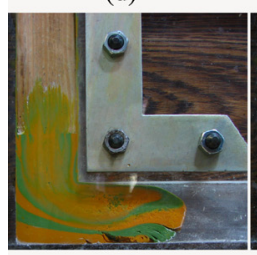

(g)



(b)

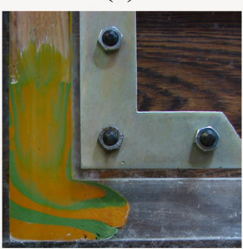

(e)

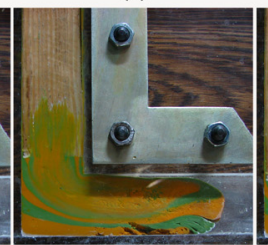

(h)

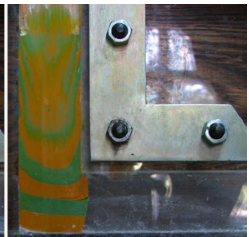

(c)

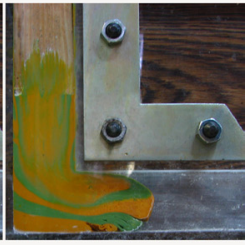

(f)

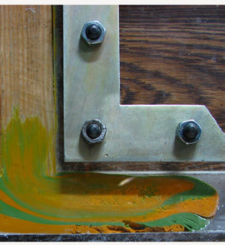

(i)

Fig. 8. Successive stages (a) - (i) of die channel filling during ECAE of a layered model through a die with a rectangular cross-section and a channel intersection angle $2 \theta=90^{\circ}$, where initial layers of the workpiece model were oriented perpendicular to the inlet channel; inlet is from the top and outlet is to the right.



Fig. 9. Physical model of a layered workpiece after ECAE of a layered plasticine model through a die with circular cross-section and channel intersection angle $2 \theta=90^{\circ}$, where initial layers of the workpiece model were oriented perpendicular to the inlet channel; inlet is from the top.

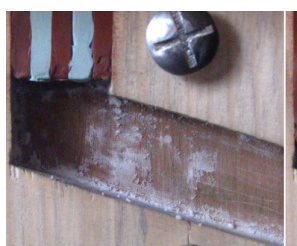

(a)

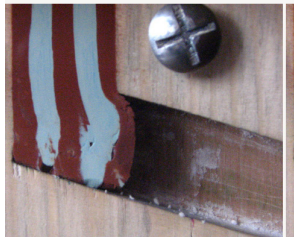

(d)



(g)

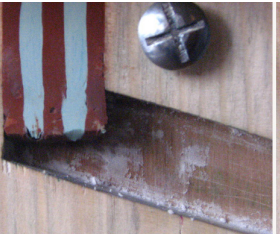

(b)

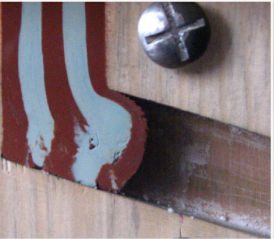

(e)

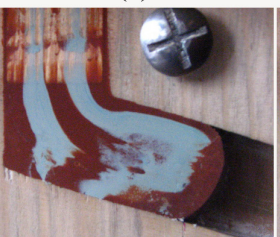

(h)

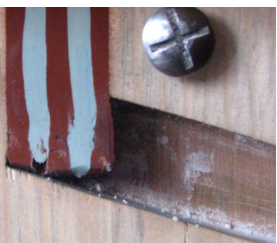

(c)

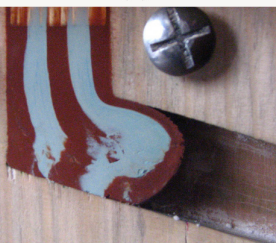

(f)

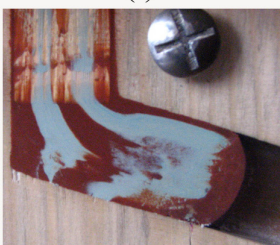

(i)
Fig. 10. Successive stages (a) - (i) of filling the die channels during ECAE of a layered model through a die with rectangular crosssection and channel intersection angle $2 \theta=105^{\circ}$, where initial layers of the model were oriented parallel to the inlet channel; inlet is from the top and outlet is to the right.

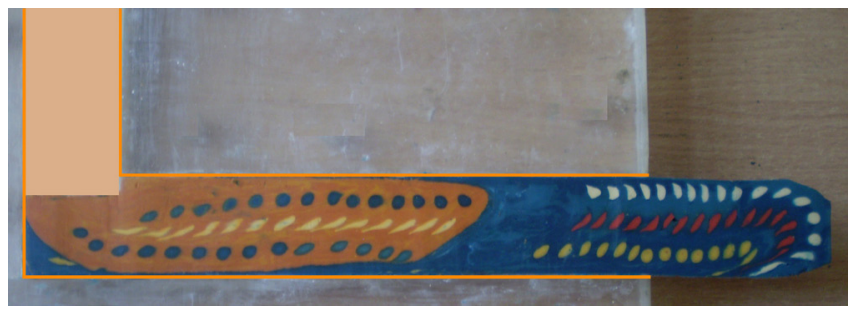

Fig. 11. The scheme of successive ECAE of two workpieces with initial circular gridlines, which illustrates stationary plastic flow of the second (left) workpiece model with back-pressure, caused by the first (right) model at the end of outlet channel; inlet is from the top and outlet is to the right. 


\section{References}

1. W. Z. Han, Z.F. Zhang, S.D. Wu, S.X. Li. Mat.Sci. Eng. A-Struct. 476(1-2), 224-229 (2008), doi:10.1016/j.msea.2007.04.114.

2. A. Hasani, R. Lapovok, L.S. Tóth, A. Molinari. Scripta Mater. 58(9), $771-774$ (2008), doi:10.1016/j.scriptamat.2007.12.018.

3. E. Hosseini, M. Kazeminezhad. Comp. Mater. Sci. 44(4), 1107 - 1115(2009), doi:10.1016/j.commatsci.2008.07.024.

4. B. V. Kucheryaev. Continuum Mechanics. Textbook. Study guide. Moscow, MISiS. (2006) 599 p. (in Russian). [Б. В. Кучеряев. Механика сплошных сред. Учебник. Москва, МИСИС. 2006. 599 с.]

5. A.M. Laptev, A.V. Perig, O.Yu. Vyal. Mater. Res.-Ibero-Am. J. 17(2), 359-366 (2014), doi:10.1590/S1516-14392013005000187.

6. A. V. Perig, A. M. Laptev, N. N. Golodenko, Y. A. Erfort, E. A. Bondarenko. Mat.Sci. Eng. A-Struct. 527(16-17), 3769 - 3776 (2010), doi:10.1016/j.msea.2010.03.043.

7. A.V. Perig, I.G. Zhbankov, V.A. Palamarchuk. Mater. Manuf. Process. 28(8), 910-915 (2013), doi:10.1080/10426914.2013.792420.

8. A.V. Perig, I.G. Zhbankov, I.A. Matveyev, V.A. Palamarchuk. Mater. Manuf. Process. 28(8), 916-922 (2013), doi:10.1080/10426914.2013.792417.

9. A. V. Perig, A.M. Laptev. J Braz.Soc. Mech. Sci. Eng. 36(3), 469 - 476 (2014), doi:10.1007/s40430-013-0121-z.

10. A.V. Perig, N.N. Golodenko. Chem.Eng. Commun. 201(9), 1221-1239 (2014), doi:10.1080/00986445.2014.894509.

11. A. V. Perig, N. N. Golodenko. Int. J. Adv. Manuf. Technol. 74(5-8), 943 - 962 (2014), doi:10.1007/s00170-014-5827-2.

12. A. V. Perig. Mater. Res.-Ibero-Am. J. 17(5), 1226-1237 (2014), doi:10.1590/1516-1439.268114.

13. A. V. Perig, A. F. Tarasov, I. G. Zhbankov, S. N. Romanko. Mater. Manuf. Process. 30(2), 222-231 (2015), doi:10.1080/10426914.2013.832299.
14. A. V. Perig, N.N. Golodenko. Mech. Sci. 6(1), 41-49 (2015), doi:10.5194/ms-6-41-2015.

15. A. Perig. Mater. Res.-Ibero-Am. J. 18(3), 628 - 638 (2015), doi:10.1590/1516 - 1439.004215.

16. A. V. Perig, N.N. Golodenko. Mater. Res.-Ibero-Am. J. 19(3), 602-610 (2016), doi:10.1590/1980 - 5373-MR-2016 - 0013.

17. A. V. Perig, N. N. Golodenko. Mater. Res. Express. 3(11), 115301 (2016), doi:10.1088/2053 - 1591/3/11/115301.

18. A. V. Perig, N. N. Golodenko. Adv. Mater. Sci. Eng. 2017, 7015282 (2017), doi:10.1155/2017/7015282.

19. L.S. Tóth, R.A. Massion, L. Germain, S.C. Baik, S. Suwas. Acta Mater. 52(7), 1885-1898 (2004). doi:10.1016/j.actamat.2003.12.027.

20. S. Wolfram. Wolfram Language \& System. Wolfram (2017). http://reference.wolfram.com. Accessed 22 June 2017

21. M. A. Lavrentiev, L. A. Lusternik. A Course in the Calculus of Variations. Functions of several variables. Vol. I, Part 2. Textbook. Study guide. Moscow - Leningrad, ONTI NKTP. (1935) 400 p. (in Russian). [M.А. Лаврентьев, Л.А. Люстерник. Основы вариационного исчисления. Функции многих переменных. Учебник. Том 1. Часть 2. М.-Л., ОНТИ НКТП. 1935. 400 с.]

22. A. V. Efimov, A. F. Karakulin, A. S. Pospelov, S. V. Frolov, V.V. Lesin. Higher Mathematics for Engineering Students. Worked Examples and Problems with Elements of Theory. Part 3. Special Courses. Textbook. Study guide. Moscow, Fizmatlit Publisher. (2002) 576 p. (in Russian). [А.В. Ефимов, А.Ф. Каракулин, А.С. Поспелов, С.В. Фролов, В.В. Лесин. Сборник задач по математике для втузов. Часть 3. Учебное пособие. М., Физматлит. 2002. 576 с.]

23. V. De Pierre, F. Gurney, A.T. Male. Mathematical Calibration of the Ring Test with Bulge Formation: Technical rept. 1 Jan-30 Nov 1971. Westinghouse Astronuclear Lab Pittsburgh PA. (1972) 38 p. (Number: AD0750885). 